\title{
Accuracy of hyaluronic acid level for predicting liver fibrosis stages in patients with hepatitis $\mathbf{C}$ virus
}

\author{
Philippe Halfon*1, Marc Bourlière ${ }^{2}$, Guillaume Pénaranda1, \\ Romaric Deydier ${ }^{1}$, Christophe Renou ${ }^{3}$, Danielle Botta-Fridlund ${ }^{4}$, \\ Albert Tran ${ }^{5}$, Isabelle Portal ${ }^{4}$, Isabelle Allemand ${ }^{4}$, Alessandra Rosenthal- \\ Allieri $^{5}$ and Denis Ouzan 6
}

\begin{abstract}
Address: ${ }^{1}$ Department of virology, Alphabio Laboratory, Marseille, France, ${ }^{2}$ Department of Hepato-Gastroenterology, Saint-Joseh Hospital, Marseille, France, ${ }^{3}$ Department of Hepato-Gastroenterology, Hyères Hospital, Hyères, France, ${ }^{4}$ Department of Hepato-Gastroenterology, La Conception Hospital, Marseille, France, ${ }^{5}$ Department of Hepato-Gastroenterology, Archet Hospital, Nice, France and ${ }^{6}$ Department of HepatoGastroenterology, Arnault Tzanck Institute, Saint Laurent du Var, France

Email: Philippe Halfon* - philippe.halfon@alphabio.fr; Marc Bourlière - mbourliere@hopital-saint-joseph.fr;

Guillaume Pénaranda - g.penaranda@alphabio.fr; Romaric Deydier - r.deydier@alphabio.fr; Christophe Renou - crenou@ch-hyeres.fr; Danielle Botta-Fridlund - dbotta@mail.ap-hm.fr; Albert Tran - tran@unice.fr; Isabelle Portal - g.penaranda@alphabio.fr; Isabelle Allemand - g.penaranda@alphabio.fr; Alessandra Rosenthal-Allieri - Alessandra.Rosenthal-Allieri@unice.fr; Denis Ouzan - denis.ouzan@wanadoo.fr

* Corresponding author
\end{abstract}

Published: II July 2005

Comparative Hepatology 2005, 4:6 doi:10.1 186/1476-5926-4-6
Received: 07 April 2005

Accepted: II July 2005

This article is available from: http://www.comparative-hepatology.com/content/4/1/6

(c) 2005 Halfon et al; licensee BioMed Central Ltd.

This is an Open Access article distributed under the terms of the Creative Commons Attribution License (http://creativecommons.org/licenses/by/2.0), which permits unrestricted use, distribution, and reproduction in any medium, provided the original work is properly cited.

\begin{abstract}
Background: In patients with chronic hepatitis $C$ virus, liver biopsy is the gold standard for assessing liver disease stage; nevertheless, it is prone to complications, some of them serious. Noninvasive methods have been proposed as surrogate markers for liver fibrosis. It was shown that serum hyaluronic acid (HA) level increases with the development for liver fibrosis. The aim of this study was to evaluate the diagnostic value of $\mathrm{HA}$ as well as to determine the HA level cut-off for predicting the presence or absence of fibrosis, severe fibrosis, and cirrhosis.

Results: 405 patients with chronic hepatitis $C$ were prospectively included with biomarker measurement and liver biopsy done the same day: $15 \mathrm{I}$ in the training set (only biopsy lengths of 25 $\mathrm{mm}$ or more) and 254 in the validation set. For the discrimination of significant fibrosis, severe fibrosis, and cirrhosis in the training set, the areas under curve (AUCs) were $0.75 \pm 0.03,0.82 \pm$ 0.02 , and $0.89 \pm 0.03$, respectively. Absence of significant fibrosis, severe fibrosis, and cirrhosis can be predicted by HA levels of 16,25 , and $50 \mu \mathrm{g} / \mathrm{l}$, respectively (with negative predictive values of $82 \%, 89 \%$, and $100 \%$, in the same order). Presence of significant fibrosis, severe fibrosis, and cirrhosis can be predicted by HA levels of $12 \mathrm{I}, 160$, and $237 \mu \mathrm{g} / \mathrm{l}$, respectively (with positive predictive values of $94 \%, 100 \%$, and $57 \%$, in the same order).

Conclusion: In the validation set, $\mathrm{HA}$ was accurate in predicting significant fibrosis, severe fibrosis, and cirrhosis with AUCs of $0.73,0.77$, and 0.97 , respectively. Moreover, accurate HA level cut-offs were defined for predicting significant fibrosis, severe fibrosis, and cirrhosis. Thus, the study supports that HA level may be clinically useful as a non-invasive marker for liver fibrosis and/or cirrhosis.
\end{abstract}




\section{Background}

Liver biopsy is currently recommended as the gold standard method of staging fibrosis in patients with chronic hepatitis $C[1,2]$. The risk of developing cirrhosis depends on the stage (degree of fibrosis) and the grade (degree of inflammation and necrosis) observed in the initial liver biopsy $[3,4]$. This procedure, however, is invasive and has potential complications $[5,6]$. Non-invasive approaches developed to assess histological samples include clinical symptoms, routine laboratory tests, and radiolographic imaging [7-10]. Several clinical studies have attempted to identify serum markers that correlate with the degree of fibrosis and thus could be used, with feasibility, in conjunction with or in place of a liver biopsy $[2-4,6,8,9]$. The serum markers of fibrogenesis include platelet count [11], prothrombin time [12], the ratio of alanine aminotransferase and aspartate aminotransferase levels [8], gammaglutamyl transferase level [13], and serum albumin level [14]. Fibrotest (FT) is a simple non-invasive panel of biochemical markers for fibrosis and activity [15].

Another non-invasive approach relies on the measurement of substances that regulate fibrosis or participate in the generation of the liver extracellular matrix. The most applicable include hyaluronic acid (HA) [16], type IV collagen [17], N-terminal propeptide of type III procollagen [18], metalloproteinases [19], inhibitors of metalloproteinases [19], and growth-transforming factor beta [20]. HA is a high molecular weight glycosaminoglycan, which is an essential component of extracellular matrix in virtually every tissue in the body [21]. In the liver, HA is mostly synthesized by the hepatic stellate cells and degraded by the sinusoidal endothelial cells [6]. HA levels are increased in chronic liver diseases [6]. In patients with chronic hepatitis $\mathrm{C}$ virus (HCV), HA levels increase with the development of liver fibrosis. Moreover, in patients with cirrhosis, HA levels correlate with clinical severity $[7,10,11]$.

The first aim of this study was to evaluate the diagnostic value of HA for significant fibrosis (F2-F4), severe fibrosis, (F3F4) and cirrhosis (F4), in patients with HCV infection. The second aim was to determine the serum HA level cutoff to predict both presence and absence of F2-F4, F3F4, and F4.

\section{Results \\ Patients}

The cohort included 405 patients. Table 1 shows the patient characteristics at the time of liver biopsy. The training and validation sets did not significantly differ in any of the assessed variables. Of the patients, 47\% (190/ 405) had significant fibrosis (F2-F4), 24\% (99/405) had severe fibrosis (F3F4), and 6\% (25/405) had cirrhosis.

\section{Hyaluronic acid and fibrosis in the training set}

Figure 1 shows HA levels and stages of fibrosis are well correlated (Spearman $\mathrm{r}=0.55-\mathrm{p}<.0001$ ). Although there is an overlap between HA levels and fibrosis determined by liver biopsy, there is a significant increase in HA levels when considering F0 to F4 scores (Kruskal-Wallis $p<0.0001)$.

\section{Fibrosis, severe fibrosis, and cirrhosis diagnosis}

Figure 2 and 3 shows receiver operating characteristic curves of discriminatory values of $\mathrm{HA}$ according to the severity of liver fibrosis in the training and validation sets. For the discrimination of fibrosis, severe fibrosis, and cirrhosis in the training set, areas under curve (AUCs) were $($ Mean \pm SE) $0.75 \pm 0.03,0.82 \pm 0.02$, and $0.89 \pm 0.03$ respectively. In the validation set, AUCs were $0.73 \pm 0.03$, $0.77 \pm 0.04$, and $0.97 \pm 0.04$, respectively.

Table I: Characteristics of the 405 patients at the time of liver biopsy (comparison between the training and the validation sets).

\begin{tabular}{|c|c|c|c|}
\hline Characteristics & Training set $(n=151)$ & Validation set $(n=254)$ & All patients $(n=405)$ \\
\hline Age (Mean \pm SD) & $51 \pm 14$ & $47 \pm 12$ & $49 \pm 13$ \\
\hline Male (n (\%)) & $82(54)$ & $133(52)$ & $215(53)$ \\
\hline $\mathrm{HA}(\mu \mathrm{g} / \mathrm{l})($ Mean $\{95 \% \mathrm{Cl}\})$ & $63\{47 ; 79\}$ & $53\{41 ; 65\}$ & $57\{47 ; 67\}$ \\
\hline \multicolumn{4}{|l|}{ Stage of fibrosis (n (\%)) } \\
\hline 0 & $28(19)$ & $33(13)$ & $61(15)$ \\
\hline 1 & $51(34)$ & $103(4 I)$ & $154(38)$ \\
\hline 2 & $33(22)$ & $58(23)$ & $91(23)$ \\
\hline 3 & $27(18)$ & $47(18)$ & 74 (18) \\
\hline 4 & $12(7)$ & $13(5)$ & $25(6)$ \\
\hline
\end{tabular}




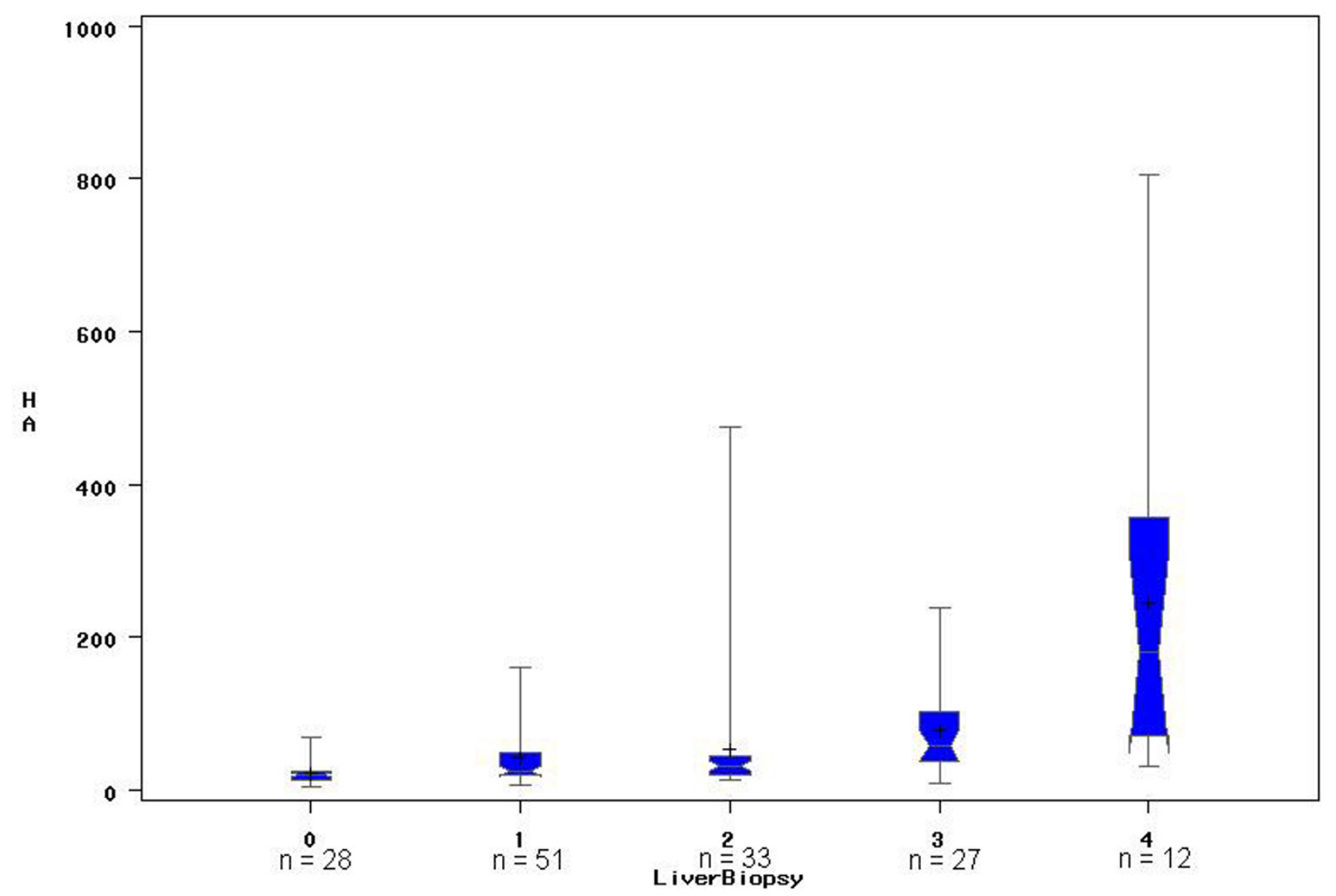

Figure I

Box \& Whisker plot representing the relation between the stage of fibrosis and HA level. The line through the box is the median; the top and bottom edges of each box represent the $25^{\text {th }}$ and $75^{\text {th }}$ percentiles, giving the interquartile range; and the cross in the box is the mean. The vertical lines at each side of the box represent distribution from the quartile to the farthest observation. The curve represents the HA median value of each fibrosis stage (F0: $20 \mu \mathrm{g} / \mathrm{l}, \mathrm{FI}: 25 \mu \mathrm{g} / \mathrm{l}, \mathrm{F} 2: 30 \mu \mathrm{g} / \mathrm{l}, \mathrm{F3}: 58 \mu \mathrm{g} / \mathrm{l}$, and F4: $180 \mu \mathrm{g} / \mathrm{l})$. The relation between the stages of fibrosis and HA level was statistically significant (Kruskal-Wallis $-p<$ $0.000 \mathrm{I})$. Spearman rank correlation coefficient $(r)$ between the stage of fibrosis and HA level was 0.55 .

\section{Fibrosis}

Two cut-off values were chosen for identifying absence (less than $16 \mu \mathrm{g} / \mathrm{l}$ ) and presence (greater than $121 \mu \mathrm{g} / \mathrm{l}$ ) of significant fibrosis (F2-F4). Applying the lower cut-off, the presence of significant fibrosis could be excluded with a high certainty as only $3(17 \%)$ of the 18 patients with an HA level below $16 \mu \mathrm{g} / \mathrm{l}$ had significant fibrosis, with a negative predictive value (NPV) of $83 \%$. In the validation set, $11(18 \%)$ of 60 patients with a score below $16 \mu \mathrm{g} / \mathrm{l}$ had significant fibrosis (NPV of 82\%). Applying the high cutoff to the training group (HA greater than $121 \mu \mathrm{g} / \mathrm{l}$ ), only $2(13 \%)$ of the 15 patients with HA greater than $121 \mu \mathrm{g} / \mathrm{l}$ had no fibrosis, with a positive predictive value (PPV) of
$87 \%$. In the validation set, 16 of the 17 patients with HA greater than $121 \mu \mathrm{g} / \mathrm{l}$ had significant fibrosis (PPV of 94\%) (Table 2).

\section{Severe fibrosis}

As for significant fibrosis diagnosis, 2 cut-off values were chosen for identifying absence (less than $25 \mu \mathrm{g} / \mathrm{l}$ ) and presence (greater than $160 \mu \mathrm{g} / \mathrm{l}$ ) of severe fibrosis (F3F4). Applying the lower cut-off, only 3 (5\%) of the 64 patients with HA lower than $25 \mu \mathrm{g} / \mathrm{l}$ had severe fibrosis (NPV of $95 \%)$. In the validation set, only $13(11 \%)$ of the 123 patients with HA lower than $25 \mu \mathrm{g} / \mathrm{l}$ had severe fibrosis (NPV of $89 \%$ ). Applying the higher cut-off (HA greater 


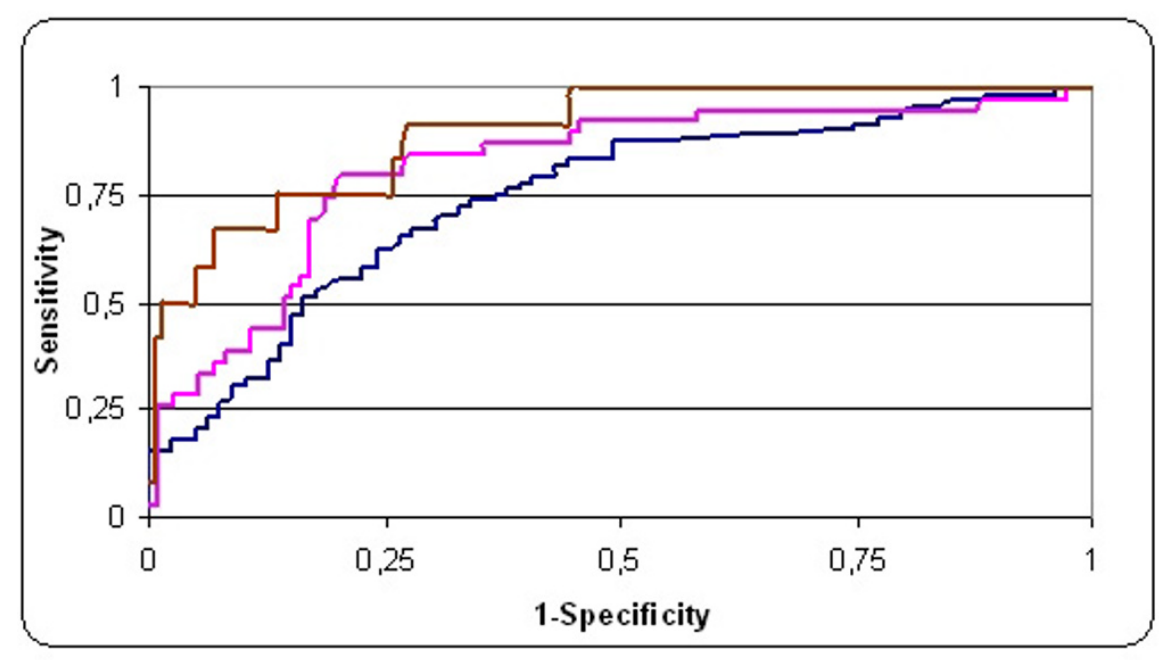

— F2F4 AUC $0.75+/-0.04$

— F3F4 AUC $0.82+/-0.04$

- F4 AUC $0.89+1-0.06$

\section{Figure 2}

Receiver operating characteristic curves of HA for the prediction of significant fibrosis (F2-F4), severe fibrosis (F3F4), and cirrhosis (F4) in the training set.

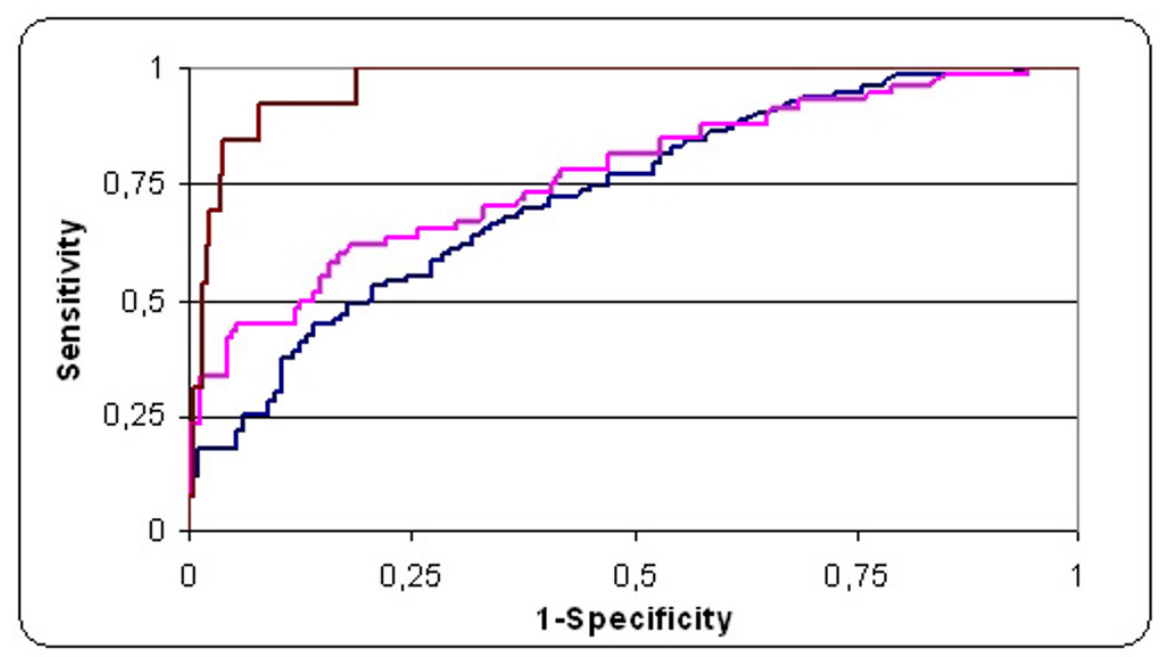

— F2F4 AUC $0.73+1-0.03$

- F3F4 AUC $0.77+1-0.04$

- F4 AUC $0.97+1-0.04$

\section{Figure 3}

Receiver operating characteristic curves of HA for the prediction of significant fibrosis (F2-F4), severe fibrosis (F3F4), and cirrhosis (F4) in the validation set. 
Table 2: Diagnostic performance of HA in the validation set.

\begin{tabular}{|c|c|c|c|c|c|c|}
\hline HA cut-off & $\begin{array}{l}\text { Sensitivity } \\
\text { (\%) }\end{array}$ & $\begin{array}{l}\text { Specificity } \\
\text { (\%) }\end{array}$ & $\begin{array}{l}\text { NPV } \\
\text { (\%) }\end{array}$ & $\begin{array}{l}\text { PPV } \\
\text { (\%) }\end{array}$ & $\begin{array}{l}\text { Population involved } \\
\text { (\%) }\end{array}$ & Interpretation \\
\hline$<16$ & 91 & 36 & 82 & 55 & 24 & Absence of fibrosis (FOFI) (82\% certainty) \\
\hline$>12 \mid$ & 14 & 99 & 57 & 94 & 7 & Presence of fibrosis (F2) ( $94 \%$ certainty) \\
\hline$\leq 25$ & 78 & 53 & 89 & 34 & 46 & Absence of severe fibrosis (FOFIF2) (89\% certainty) \\
\hline$>160$ & 22 & 100 & 81 & 100 & 5 & Presence of severe fibrosis (F3) ( $100 \%$ certainty) \\
\hline$\leq 50$ & 100 & 79 & 100 & 20 & 75 & Absence of cirrhosis (FOFIF2F3) ( $100 \%$ certainty) \\
\hline$>237$ & 31 & 99 & 96 & 57 & 3 & Presence of cirrhosis (F4) (57\% certainty) \\
\hline
\end{tabular}

Note I: Accuracy $=$ Sensitivity + Specificity + NPV + PPV. Note 2: Population involved stands for the proportion of patients who fall in the corresponding cut-off.

than $160 \mu \mathrm{g} / \mathrm{l}$ ) to the training set, 10 (NPV of $91 \%$ ) out of 11 patients with $\mathrm{HA}$ greater than $160 \mu \mathrm{g} / \mathrm{l}$ had severe fibrosis, and none of the 13 patients with HA greater than $160 \mu \mathrm{g} / \mathrm{l}$ from the validation set had severe fibrosis (PPV of $100 \%$ ) (Table 2).

\section{Cirrhosis}

Two cut-off values were chosen for identifying absence (less than $50 \mu \mathrm{g} / \mathrm{l}$ ) and presence (greater than $237 \mu \mathrm{g} / \mathrm{l}$ ) of cirrhosis (F4). Applying the lower cut-off, 100 (NPV of $99 \%$ ) of the 101 patients with HA lower than $264 \mu \mathrm{g} / \mathrm{l}$ had no cirrhosis. In the validation set, none of the patients with HA lower than $50 \mu \mathrm{g} / \mathrm{l}$ had cirrhosis (NPV of 100\%). When applying the higher cut-off $(237 \mu \mathrm{g} / \mathrm{l})$ to the training set, a fair PPV of 71\% was obtained for predicting the presence of cirrhosis. The PPV was lower when applying the cut-off to the validation set (PPV of 57\%) (Table 2).

\section{Discussion}

Combining HA level with other serum markers for assessing liver fibrosis has been considered in some other studies [22,23]. One of the interests of our study was to focus on the diagnostic accuracy of HA alone in predicting fibrosis and cirrhosis in $\mathrm{HCV}$-infected patients.

In the present study, HA level was accurate in predicting significant fibrosis, severe fibrosis, and cirrhosis, with AUCs of $0.75,0.82$, and 0.89 , respectively, in the training set; and of $0.73,0.77$, and 0.97 , respectively, in the validation set. Using values below the lower cut-off level or above the higher cut-off level, one could predict absence or presence of significant fibrosis, severe fibrosis, and cirrhosis in 31\%, 51\%, and 78\%, respectively, in the validation set patients. Therefore, it is likely that the association of HA level with the degree of hepatic fibrosis represents an indirect one, expressing the functional correlation between fibrosis and both the concomitant capillarization and hepatic hemodynamic changes.

Significant fibrosis can be predicted by a HA level of $<16$ $\mu \mathrm{g} / \mathrm{l}$ for its absence (NPV of $82 \%$ ) and of $>121 \mu \mathrm{g} / \mathrm{l}$ for its presence (PPV of 94\%) in the validation set. Severe fibrosis can be predicted by a HA level of $\leq 25 \mu \mathrm{g} / \mathrm{l}$ for its absence (NPV of $89 \%$ ) and of $>160 \mu \mathrm{g} / \mathrm{l}$ for its presence (PPV of 100\%). Cirrhosis can be predicted by an HA level of $\leq 50 \mu \mathrm{g} / \mathrm{l}$ for its absence (NPV of 100\%) and of $>237$ $\mu \mathrm{g} / \mathrm{l}$ for its presence (PPV of $57 \%$ ). Considering a serum HA cut-off of $60 \mu \mathrm{g} / \mathrm{l}$ for absence of cirrhosis diagnosis, our data are in the same range as those of other studies $[3,24]$.

A cut-off value of $110 \mu \mathrm{g} / \mathrm{l}$ was suggested for separating patients with and without cirrhosis [18]. Taking in consideration this cut-off in our cohort of patients, a misclassification of cirrhotic patients was observed in 23\% (3/13) (sensitivity of $77 \%$ ) of patients with proven cirrhosis. This difference may be due to the use of a different HA assay.

Our study included a sufficient proportion of patients with significant fibrosis: $47 \%$ in the training set and $46 \%$ in the validation set; however, the proportion of patients with cirrhosis was low in the two sets: $7 \%$ and 5\%, respectively. The second limitation of this study is the number of unclassified patients (between 22\% and 69\%).

\section{Conclusion}

This study showed that significant fibrosis, severe fibrosis, and cirrhosis can be predicted by serum HA levels in patients with HCV infection. The notion of routinely measuring a marker that reflects the function of the sinusoidal endothelial cells, rather than the hepatocytes themselves, is an exciting concept. Serum HA would be clinically useful as a non-invasive marker of liver fibrosis or cirrhosis in HCV-infected patients. It suffers from the need to limit, as much as possible, potential confounding variables such as the effects of exercise and eating.

Further studies conducted in a large cohort of cirrhosis patients are needed to corroborate this study, namely because few of our patients had cirrhosis and the cut-off levels must be considered in an independent study. Moreover, a comparison of HA levels with other non-invasive 
markers and scores of liver fibrosis (FT, APRI, Forns, ageplatelets index, platelet count, prothrombin time, etc.) would be of interest.

\section{Methods}

\section{Study participants}

The cohort included 405 patients (mean age $49 \pm 13$ years, 53\% men) with HCV infection between November 2002 and December 2003, in five centers in southern France [Conception Hospital and Saint-Joseph Hospital (Marseille), Archet Hospital (Nice), Hyères Hospital (Hyères), and Arnault Tzanck Institute (St Laurent du Var)]. HA assessment was evaluated with data from 151 patients (training group) and was validated in the remaining 254 patients (validation group). Only biopsy lengths of 25 $\mathrm{mm}$ or more were included in the training group, in accordance with a recent study [25]; the remaining patients were included in the validation set. None of the patients had joint injuries, based on clinical examinations and inflammatory markers estimated at the time of inclusion in the study. None of the patients had renal impairment, based on normal creatinine clearance (Cockroft calculation).

\section{Liver biopsies}

Liver biopsy examination was performed in each center by evaluating the stage of fibrosis and grade of activity according to the METAVIR scoring system [26,27]. Liver biopsies were histologically assessed in the local centers and a second assessment of each biopsy was done in a reference laboratory. The second assessments were done by the same pathologist. In this study, all liver biopsies were re-staged by the central reference laboratory $(n=405)$. No liver biopsies were found with more than one-stage difference between the local pathologist and the reference pathologist. One-stage discordance is considered pathology-dependent and thus not considered significant. Fibrosis was staged on a scale of 0 to 4 : F0 = no fibrosis, F1 = portal fibrosis without septa, F2 = portal fibrosis and few septa, F3 = numerous septa without cirrhosis, F4 = cirrhosis.

\section{Hyaluronic acid}

HA levels were measured by Alphabio Laboratories, Marseille, with the Corgenix Hyaluronic Acid Test Kit, Corgenix Inc., CO, following the manufacturer's instructions (patients in fasting conditions, no physical effort). Each HA level was measured in duplicate (range 1 to $871 \mu \mathrm{g} / \mathrm{l}$ ) and a pool control set was used. All serum samples were obtained on the day of liver biopsy.

\section{Statistical analysis}

The association between HA levels and liver biopsy staging was measured with the Kruskal-Wallis multiple comparison test and with the Spearman rank correlation coefficient. A $p<0.05$ was considered significant. Respective diagnostic values were reported by the area under the receiver operating characteristic curves (AUC) ( \pm standard error mean), NPV, PPV, sensitivity, and specificity.

\section{Authors' contributions}

$\mathrm{PH}$ and $\mathrm{MB}$ conceived and wrote the manuscript. RD, CR, DBF, AT, IP, IA, ARA and DO were responsible for the patient drafting, carried out biochemical analysis, participated in the coordination of the study, and drafted the paper. GP performed the statistical analysis and participated in the writing of the paper. All authors read and approved the final manuscript

\section{Acknowledgements}

We thank Denice Taylor (Corgenix Inc., CO) for kindly providing hyaluronic acid test kit.

\section{References}

I. Parillo R: Long term effect of antiviral therapy on liver histology in chronic hepatitis C. EASL; 2004.

2. Pares A, Deulofeu R, Gimenez A, Caballeria L, Bruguera M, Caballeria J, Ballesta AM, Rodes J: Serum hyaluronate reflects hepatic fibrogenesis in alcoholic liver disease and is useful as a marker of fibrosis. Hepatology 1996, 24(6): |399-| 403.

3. Oberti F, Valsesia E, Pilette C, Rousselet MC, Bedossa P, Aube C, Gallois Y, Rifflet H, Maiga MY, Penneau-Fontbonne D, Cales P: Noninvasive diagnosis of hepatic fibrosis or cirrhosis. Gastroenterology 1997, II3(5): 1609-1616.

4. Wai CT, Greenson JK, Fontana RJ, Kalbfleisch JD, Marrero JA, Conjeevaram HS, Lok AS: A simple noninvasive index can predict both significant fibrosis and cirrhosis in patients with chronic hepatitis C. Hepatology 2003, 38(2):5।8-526.

5. Cadranel JF: [Good clinical practice guidelines for fine needle aspiration biopsy of the liver: past, present and future]. Gastroenterol Clin Biol 2002, 26( I 0):823-824.

6. Guechot J, Loria A, Serfaty L, Giral P, Giboudeau J, Poupon R: Serum hyaluronan as a marker of liver fibrosis in chronic viral hepatitis C: effect of alpha-interferon therapy. I Hepatol 1995 , 22(I):22-26.

7. Gibson PR, Fraser JR, Brown TJ, Finch CF, Jones PA, Colman JC, Dudley FJ: Hemodynamic and liver function predictors of serum hyaluronan in alcoholic liver disease. Hepatology 1992, I 5(6): 1054-1059.

8. Forns X, Ampurdanes S, Llovet JM, Aponte J, Quinto L, MartinezBauer E, Bruguera M, Sanchez-Tapias JM, Rodes J: Identification of chronic hepatitis $\mathrm{C}$ patients without hepatic fibrosis by a simple predictive model. Hepatology 2002, 36(4 Pt I):986-992.

9. Imbert-Bismut $F$, Ratziu $V$, Pieroni L, Charlotte F, Benhamou $Y$, Poynard $\mathrm{T}$ : Biochemical markers of liver fibrosis in patients with hepatitis C virus infection: a prospective study. Lancet 200I, 357(9262): 1069-1075.

10. Poupon RE, Balkau B, Guechot J, Heintzmann F: Predictive factors in ursodeoxycholic acid-treated patients with primary biliary cirrhosis: role of serum markers of connective tissue. Hepatology 1994, 19(3):635-640.

II. Korner T, Kropf J, Gressner AM: Serum laminin and hyaluronan in liver cirrhosis: markers of progression with high prognostic value. J Hepatol 1996, 25(5):684-688.

12. Benlloch S, Berenguer M, Prieto M, Rayon JM, Aguilera V, Berenguer $\mathrm{J}$ : Prediction of fibrosis in $\mathrm{HCV}$-infected liver transplant recipients with a simple noninvasive index. Liver Transp/ 2005, I I (4):456-462.

13. Silva IS, Ferraz ML, Perez RM, Lanzoni VP, Figueiredo VM, Silva AE: Role of gamma-glutamyl transferase activity in patients with chronic hepatitis C virus infection. J Gastroenterol Hepatol 2004, 19(3):3|4-3|8.

14. Lu LG, Zeng MD, Wan MB, Li CZ, Mao YM, Li JQ, Qiu DK, Cao AP, Ye J, Cai X, Chen CW, Wang JY, Wu SM, Zhu JS, Zhou XQ: Grading and staging of hepatic fibrosis, and its relationship with non- 
invasive diagnostic parameters. World / Gastroenterol 2003, 9(II):2574-2578.

15. Poynard T, Imbert-Bismut F, Munteanu M, Messous D, Myers RP, Thabut D, Ratziu V, Mercadier A, Benhamou Y, Hainque B: Overview of the diagnostic value of biochemical markers of liver fibrosis (FibroTest, HCV FibroSure) and necrosis (ActiTest) in patients with chronic hepatitis C. Comp Hepatol 2004, 3(I):8.

16. Guechot J, Poupon RE, Giral P, Balkau B, Giboudeau J, Poupon R: Relationship between procollagen III aminoterminal propeptide and hyaluronan serum levels and histological fibrosis in primary biliary cirrhosis and chronic viral hepatitis C. J Hepatol I 994, 20(3):388-393.

17. Santos VN, Leite-Mor MM, Kondo M, Martins JR, Nader H, Lanzoni VP, Parise ER: Serum laminin, type IV collagen and hyaluronan as fibrosis markers in non-alcoholic fatty liver disease. Braz J Med Biol Res 2005, 38(5):747-753.

18. Guechot J, Laudat A, Loria A, Serfaty L, Poupon R, Giboudeau J: Diagnostic accuracy of hyaluronan and type III procollagen amino-terminal peptide serum assays as markers of liver fibrosis in chronic viral hepatitis $C$ evaluated by ROC curve analysis. Clin Chem 1996, 42(4):558-563.

19. El-Gindy I, El Rahman AT, El-Alim MA, Zaki SS: Diagnostic potential of serum matrix metalloproteinase-2 and tissue inhibitor of metalloproteinase-I as non-invasive markers of hepatic fibrosis in patients with $\mathrm{HCV}$ related chronic liver disease. Egypt J Immunol 2003, I (1):27-35.

20. Wang H, Mengsteab S, Tag CG, Gao CF, Hellerbrand C, Lammert F, Gressner AM, Weiskirchen R: Transforming growth factorbetal gene polymorphisms are associated with progression of liver fibrosis in Caucasians with chronic hepatitis C infection. World J Gastroenterol 2005, I I ( I3): 1929-1936.

21. Lindqvist $U$, Laurent TC: Serum hyaluronan and aminoterminal propeptide of type III procollagen: variation with age. Scand J Clin Lab Invest 1992, 52(7):613-621.

22. Patel K, Gordon SC, Jacobson I, Hezode C, Oh E, Smith KM, Pawlotsky JM, McHutchison JG: Evaluation of a panel of non-invasive serum markers to differentiate mild from moderate-toadvanced liver fibrosis in chronic hepatitis C patients. J Hepatol 2004, 41 (6):935-942.

23. Rosenberg WM, Voelker M, Thiel R, Becka M, Burt A, Schuppan D, Hubscher S, Roskams T, Pinzani M, Arthur MJ: Serum markers detect the presence of liver fibrosis: a cohort study. Gastroenterology 2004, I 27(6): | 704-I7|3.

24. McHutchison JG, Blatt LM, de Medina M, Craig JR, Conrad A, Schiff ER, Tong MJ: Measurement of serum hyaluronic acid in patients with chronic hepatitis $\mathbf{C}$ and its relationship to liver histology. Consensus Interferon Study Group. J Gastroenterol Hepatol 2000, I5(8):945-95I.

25. Bedossa P, Dargere D, Paradis V: Sampling variability of liver fibrosis in chronic hepatitis C. Hepatology 2003, 38(6): 1449-1457.

26. Intraobserver and interobserver variations in liver biopsy interpretation in patients with chronic hepatitis $\mathbf{C}$. The French METAVIR Cooperative Study Group. Hepatology I994, 20(I Pt I): I5-20.

27. Bedossa P, Poynard T: An algorithm for the grading of activity in chronic hepatitis C. The METAVIR Cooperative Study Group. Hepatology 1996, 24(2):289-293.
Publish with Biomed Central and every scientist can read your work free of charge

"BioMed Central will be the most significant development for disseminating the results of biomedical research in our lifetime. "

Sir Paul Nurse, Cancer Research UK

Your research papers will be:

- available free of charge to the entire biomedical community

- peer reviewed and published immediately upon acceptance

- cited in PubMed and archived on PubMed Central

- yours - you keep the copyright
BioMedcentral 